\title{
Cost-Effectiveness Analysis of Pharmaceutical Treatment Options in the First-Line Management of Major Depressive Disorder in Belgium
}

\author{
Lieven Annemans • Mélanie Brignone $\cdot$ \\ Sylvain Druais · Ann De Pauw · Aline Gauthier • \\ Koen Demyttenaere
}

Published online: 20 February 2014

(C) The Author(s) 2014. This article is published with open access at Springerlink.com

\begin{abstract}
Objective The objective of this study was to assess the cost effectiveness of commonly used antidepressants as first-line treatment of major depressive disorder (MDD) in Belgium.

Methods The model structure was based on a decision tree developed by the Swedish TLV (Tandvårds- och läkemedelsförmånsverket) and adapted to the Belgium healthcare setting, using primary local data on the patterns of treatment and following KCE [Federal Knowledge Center (Federaal Kenniscentrum voor de Gezondheidszorg)] recommendations. Comparators were escitalopram, citalopram, fluoxetine, paroxetine, sertraline, duloxetine, venlafaxine, and mirtazapine. In the
\end{abstract}

Electronic supplementary material The online version of this article (doi:10.1007/s40273-014-0138-x) contains supplementary material, which is available to authorized users.

L. Annemans $(\square)$

Ghent University Hospital, Block A, 2nd fl., De Pintelaan 185,

9000 Ghent, Belgium

e-mail: Lieven.annemans@ugent.be

M. Brignone

Lundbeck SAS, Issy-les-Moulineaux, France

S. Druais - A. Gauthier

Amaris, London, UK

A. De Pauw

Lundbeck Belgium, Brussels, Belgium

K. Demyttenaere

University Hospital Gasthuisberg, Leuven, Belgium model, patients not achieving remission or relapsing after remission on the assessed treatment moved to a second therapeutic step (titration, switch, add-on, or transfer to a specialist). In case of failure in the second step or following a suicide attempt, patients were assumed to be referred to secondary care. The time horizon was 1 year and the analysis was conducted from the National Institute for Health and Disability Insurance (NIHDI; national health insurance) and societal perspectives. Remission rates were obtained from the TLV network meta-analysis and risk of relapse, efficacy following therapeutic change, risk of suicide attempts and related death, utilities, costs (2012), and resources were derived from the published literature and expert opinion. The effect of uncertainty in model parameters was estimated through scenario analyses and a probabilistic sensitivity analysis (PSA).

Results In the base-case analysis, escitalopram was identified as the optimal strategy: it dominated all other treatments except venlafaxine from the NIHDI perspective, against which it was cost effective with an incremental cost-effectiveness ratio of $€ 6,352$ per quality-adjusted lifeyear (QALY). Escitalopram also dominated all other treatments from the societal perspective. At a threshold of $€ 30,000$ per QALY and from the NIHDI perspective, the PSA showed that the probability of escitalopram being identified as the optimal strategy ranged from $61 \%$ (vs. venlafaxine) to $100 \%$ (vs. fluoxetine).

Conclusion Escitalopram was associated with the highest probability of being the optimal treatment from the NIHDI and societal perspectives. This analysis, based on new Belgian clinical practice data and following KCE requirements, provides additional information that may be used to guide the choice of treatments in the management of MDD in Belgium. 


\section{Key Points for Decision Makers}

There is currently no published guideline on the management of major depressive disorder (MDD) in Belgium.

The most recent assessment of the cost effectiveness of antidepressants in Belgium was published in 2005.

Our study updates the cost-effectiveness assessment of first-line pharmaceutical treatment of MDD in Belgium, reflecting current clinical practice and considering all relevant comparators.

Our model was based on the TLV (Tandvårds- och läkemedelsförmånsverket) model developed with the aim to reassess antidepressants in Sweden following the implementation of new reimbursement rules.

In the base-case analysis, escitalopram dominated all the comparators except venlafaxine from the national health insurance (National Institute for Health and Disability Insurance; NIHDI) perspective, and all the comparators from the societal perspective.

Escitalopram was associated with the highest probability of being the optimal treatment from the NIHDI and societal perspectives.

\section{Introduction}

Major depressive disorder (MDD), or unipolar disorder, affects approximately 121 million people worldwide and 30.3 million in Europe, and places a considerable burden on society [2,3]. MDD is a mental disorder generally characterized by the presence of one pole of persistent low mood (unlike alternating episodes of low and high mood in bipolar disorder), and a loss of interest and pleasure [4, 5]. In 2011, the median prevalence was estimated at $6.9 \%$ in Europe and depression was the most important contributor to burden of disease among mental and other disorders of the brain [7.2\% of the overall European disability-adjusted life-years (DALYs), and $40.5 \%$ of the DALYs caused by mental and substance use disorders worldwide] [3, 6]. The number of deaths due to suicides in people suffering from depression is estimated at 850,000 per year worldwide [2].

In Belgium, the lifetime prevalence of MDD was estimated at $13.6 \%$ in 2004 [7] and the global costs of antidepressants represented $7.2 \%$ of the pharmaceutical expenses prescribed in ambulatory care [8]. In 2008, the Rijksinstituut voor Ziekte- en Invaliditeitsverzekering/ Institut Nationale d'Assurance Maladie et Invalidité, referred to as the National Institute for Health and Disability Insurance (NIHDI), reimbursed more than 20 antidepressants in Belgium, classified according to four main categories: tricyclic antidepressants, selective serotonin reuptake inhibitors (SSRIs), monoamine oxidase inhibitors, and others including the serotonin-norepinephrine reuptake inhibitors (SNRIs) [9]. SSRI antidepressants were introduced in the early 1990s and they accounted for $60 \%$ of the prescriptions of antidepressants in Belgium in 2009 [10, 11]. Notwithstanding the context, there is no current clear published recommendation for the management of depression in Belgium, nor is the extent to which the differences in clinical benefits between the different drugs translate into economic benefits clear. The most recently published cost-effectiveness analysis is from 2005 [12] and concluded that escitalopram was cost effective compared to citalopram (SSRI) and venlafaxine (SRNI) in the treatment of MDD in Belgium. More recent international studies reported that SSRIs were a cost-effective option, specifically escitalopram $[1,13]$. Therefore, this analysis aimed to provide a more up-to-date assessment, but also taking into account the incremental cost per quality-adjusted life-year (QALY) and the currently most prescribed antidepressants (which were based on all relevant antidepressants included in the scope of the review by the Swedish Dental and Pharmaceutical Benefits Board (Tandvårds- och läkemedelsförmånsverket; TLV) [1]).

Based on an adaptation of an existing economic evaluation [1] and new local data on the clinical management patterns of depression in Belgian care settings [14], we sought to assess the cost effectiveness of the most relevant pharmaceutical treatment options in the first-line management of MDD in Belgium.

\section{Methods}

\subsection{Overview}

The cost-effectiveness analysis was developed based on a recent model published by the Swedish Dental and Pharmaceutical Benefits Board (TLV) [1]. In addition to having been developed by a governmental health authority, the model was populated using its own network meta-analyses results, reinforcing the robustness of the analysis. Our adaptation of the TLV model and the corresponding economic analyses were performed according to the Belgian guidelines for health economic studies, established by the Federal Knowledge Center (KCE; Federaal Kenniscentrum voor de Gezondheidszorg) (see the Electronic Supplementary Material, Technical Appendix-Table I [15]), and adapted to Belgian treatment patterns, considering only two therapeutic steps. In order to reflect local practices, the 


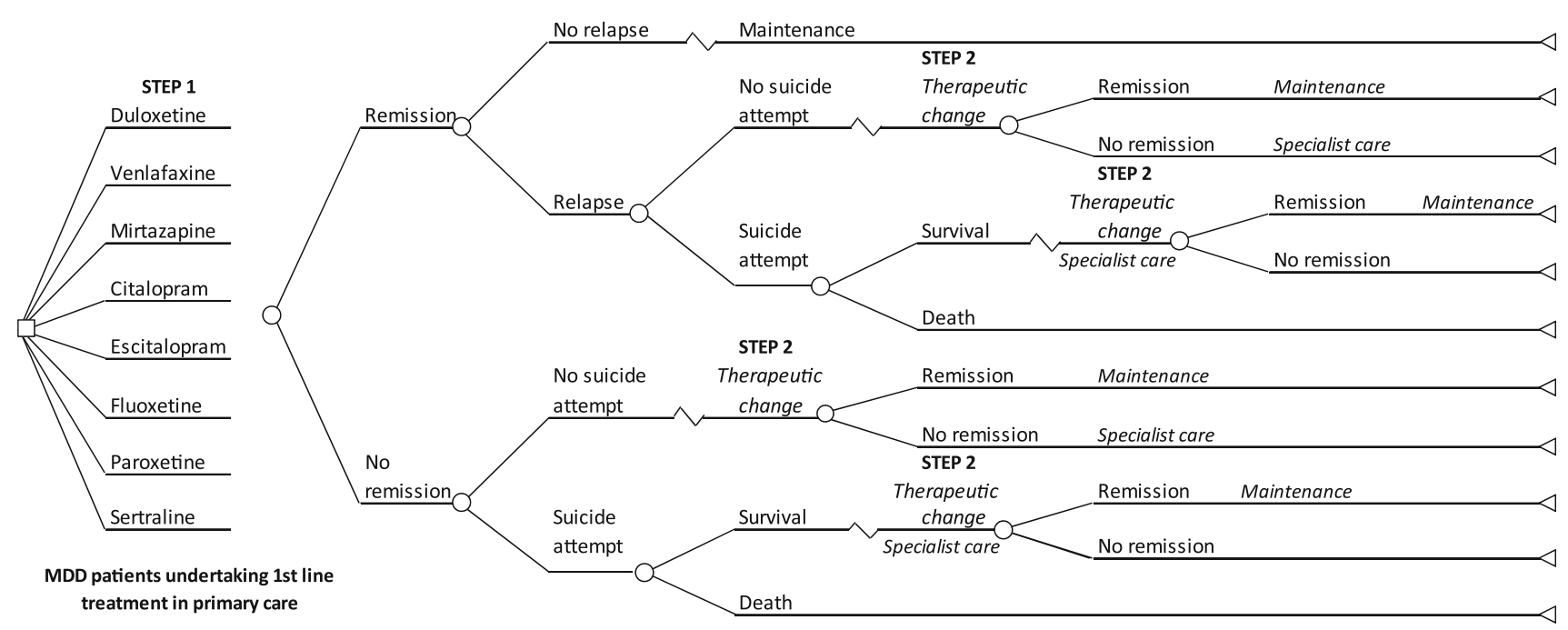

Fig. 1 Model structure. Primary care model for major depressive disorder using a time horizon of 12 months, derived from the Swedish Tandvårds- och läkemedelsförmånsverket (TLV) model and adjusted to the Belgian care settings. Two steps of therapy were considered in

treatment pathways for a typical patient with MDD in Belgium were derived from a local survey conducted in 2011 by the Department of Psychiatry of the Universitair Psychiatrisch Centrum (UPC; KU Leuven, Belgium) [14]. The most commonly used antidepressants were identified by clinical experts and included citalopram $20 \mathrm{mg} /$ day (generic), fluoxetine $20 \mathrm{mg} /$ day (generic), paroxetine $20 \mathrm{mg} /$ day (generic), sertraline $50 \mathrm{mg} /$ day (generic), duloxetine $60 \mathrm{mg} /$ day, venlafaxine $75 \mathrm{mg} /$ day (generic), mirtazapine $30 \mathrm{mg} /$ day (generic), and escitalopram $10 \mathrm{mg}$ / day. For each of these treatments, QALYs and costs (from the NIHDI and societal perspectives) for an average patient were assessed after/over 12 months.

\subsection{Decision Tree Model}

The decision tree describing possible outcomes and medical management decisions within a period of 1 year is shown in Fig. 1. Pharmacoeconomic analyses were conducted using the software Microsoft Excel ${ }^{\circledR}$, version 2007 (Microsoft Corporation, Redmont, WA, USA). Following initial treatment, patients were assumed to achieve remission or to change therapy. After achieving remission, patients could either relapse or remain on maintenance therapy until the end of the 12 months. Patients who relapsed or did not achieve remission, either due to lack of efficacy or lack of tolerability, moved to a second therapeutic step, which include one of the four following strategies if treatment was not effective: (1) increase the dose of the current therapy (titration); (2) receive another antidepressant from the same class or from another class (switch within the class or to another class); (3) add another the model. Patients who attempted suicide or failed in the second step were assumed to be transferred to specialist care. Specialist care included ambulatory care and hospitalization. $M D D$ major depressive disorder

therapy to increase the efficacy of the initiation drug, including combination with bupropion, combination with psychotherapy, or augmentation with quetiapine (add-on); or (4) switch to psychotherapy. Following expert opinion and the TLV approach, it was assumed that patients who failed to achieve remission or relapsed on the initiated treatment faced the same risk of suicide attempt regardless of the type of therapy on which they failed to achieve remission or relapsed after achieving remission.

Patients who failed to achieve remission following the second therapeutic step and patients who survived a suicide attempt were assumed to be transferred to specialist care.

\subsection{Model Parameters}

\subsubsection{Clinical Inputs}

Rates of remission on the initiated treatments were derived from the meta-analysis conducted by the TLV (see Wessling and Ramsberg, Appendix 11 [1] for details), which considered studies defining remission as a score of 7 or lower on the 17-item Hamilton Depression Rating Scale (HAMD) or a score of 12 or lower on the 10-item Montgomery-Åsberg Depression Rating Scale (MADRS). Data related to the risk of relapse, efficacy following therapeutic change, and risk of suicide attempts and related death were derived from the published literature and expert opinion.

The rate of remission in patients on escitalopram was estimated at $47.56 \%$. The range for the seven comparators was $40.21 \%$ (fluoxetine) to $45.68 \%$ (venlafaxine) (Table 1). The proportion of patients experiencing relapse was assumed to be similar across treatments and was set to 
Table 1 Clinical data and sources
NA not applicable, SNRI serotonin-norepinephrine reuptake inhibitor, SSRI selective serotonin reuptake inhibitor, $T L V$ Tandvårds- och läkemedelsförmånsverket

a SNRI: including mirtazapine

\begin{tabular}{|c|c|c|}
\hline Clinical data & Data $(\%)$ & References \\
\hline \multicolumn{3}{|l|}{ Remission rate in first therapeutic step } \\
\hline \multicolumn{3}{|l|}{ SNRIs $^{\mathrm{a}}$} \\
\hline Duloxetine & 44.99 & Wessling and Ramsberg (TLV) [1] \\
\hline Venlafaxine & 45.68 & Wessling and Ramsberg (TLV) [1] \\
\hline Mirtazapine & 45.08 & Wessling and Ramsberg (TLV) [1] \\
\hline \multicolumn{3}{|l|}{ SSRIs } \\
\hline Citalopram & 40.50 & Wessling and Ramsberg (TLV) [1] \\
\hline Escitalopram & 47.56 & Wessling and Ramsberg (TLV) [1] \\
\hline Fluoxetine & 40.21 & Wessling and Ramsberg (TLV) [1] \\
\hline Paroxetine & 42.70 & Wessling and Ramsberg (TLV) [1] \\
\hline Sertraline & 43.02 & Wessling and Ramsberg (TLV) [1] \\
\hline \multicolumn{3}{|l|}{ Remission rate in second therapeutic step } \\
\hline Switch to SNRI (venlafaxine $75 \mathrm{mg} /$ day) & 25.00 & Rush et al. (STAR*D) [18] \\
\hline Switch to SSRI (sertraline $50 \mathrm{mg} /$ day) & 26.60 & Rush et al. (STAR*D) [18] \\
\hline Switch to psychotherapy & 41.90 & Rush et al. (STAR*D) [18] \\
\hline Combination with bupropion $150 \mathrm{mg} /$ day & 39.00 & Rush et al. (STAR*D) [18] \\
\hline Combination with psychotherapy & 29.40 & Rush et al. (STAR*D) [18] \\
\hline Augmentation with quetiapine $300 \mathrm{mg} /$ day & 53.10 & Bauer et al. [19] \\
\hline \multicolumn{3}{|l|}{ Titration } \\
\hline \multicolumn{3}{|l|}{ SNRIs $^{\mathrm{a}}$} \\
\hline Duloxetine & NA & \\
\hline Venlafaxine & 37.40 & Francois et al. [20] \\
\hline Mirtazapine & 36.91 & Francois et al. [20] \\
\hline \multicolumn{3}{|l|}{ SSRIs } \\
\hline Citalopram & 23.80 & Francois et al. [20] \\
\hline Escitalopram & 36.20 & Francois et al. [20] \\
\hline Fluoxetine & 23.80 & Francois et al. [20] \\
\hline Paroxetine & 32.50 & Francois et al. [20] \\
\hline Sertraline & 32.74 & Francois et al. [20] \\
\hline \multicolumn{3}{|l|}{ Risk of relapse } \\
\hline Similar across treatment & 14.20 & Limosin et al. [16] \\
\hline \multicolumn{3}{|l|}{ Risk of suicide } \\
\hline Attempted suicide & 6.30 & Kahn et al. [17] \\
\hline Death after suicide attempt & 10.00 & Kahn et al. [17] \\
\hline
\end{tabular}

$14.2 \%$, based on a longitudinal study published by Limosin et al. [16]. Patients who relapsed were assumed to do so within 4 months of having achieved remission. As no local data regarding the incidence of fatal suicide and non-fatal suicide were identified, the publication from Khan et al. [17], who evaluated suicide based on data from US FDA-reviewed studies involving 23,201 depressive patients, was used. The authors reported a rate of suicide of 6.3 per 100 patient-years. This rate was applied to patients who relapsed or failed to achieve remission. Based on the same study, $10 \%$ of suicide attempts were assumed to lead to death.

Remission rates in the second step were mainly obtained from the Sequenced Treatment Alternatives to Relieve Depression (STAR*D) [18] study and the published literature. The STAR*D study was implemented by the National
Institute of Mental Health in the USA and aimed to compare the short- and longer-term treatment outcomes of 3,671 outpatient adults with non-psychotic depression disorder in 41 clinical sites, followed for 1 year. Thus, in case of add-on, the first-step antidepressant (which was citalopram in STAR*D) was assumed to be combined with bupropion $150 \mathrm{mg} /$ day and associated with a remission rate of $39 \%$. A similar remission rate of $41.9 \%$ was assumed in cases of transfer to psychotherapy or to specialist care. The remission rate after augmentation with quetiapine $300 \mathrm{mg} /$ day was obtained from a pooled analysis of two clinical trials assessing the efficacy of adjunctive quetiapine in MDD patients [19], as quetiapine was not used in the STAR*D study. Efficacy after titration was derived from a study by Francois et al. [20], who developed a pharmacoeconomic 
Table 2 Medical management, based on the results of the local survey [14]

\begin{tabular}{lcc}
\hline Medical management & SNRI $^{\mathrm{a}}(\%)$ & SSRI (\%) \\
\hline Reasons for change & & \\
Lack of efficacy & 59.43 & 73.32 \\
Lack of tolerability & 40.57 & 26.68 \\
Therapeutic changes & & \\
Lack of tolerability & & \\
$\quad$ Switch to SNRI & 21.94 & 53.28 \\
Switch to SSRI & 63.25 & 32.99 \\
Switch to psychotherapy & 14.81 & 13.73 \\
Lack of efficacy & & \\
Switch to SNRI & 5.41 & 19.50 \\
Switch to SSRI & 12.87 & 4.54 \\
Titration & 45.58 & 41.40 \\
Combination with bupropion & 11.19 & 9.33 \\
Combination with psychotherapy & 16.23 & 19.70 \\
Augmentation with quetiapine & 5.84 & 3.44 \\
Switch to psychotherapy & 2.89 & 2.09 \\
\hline
\end{tabular}

NA not applicable, SNRI serotonin-norepinephrine reuptake inhibitor, SSRI selective serotonin reuptake inhibitor

a SNRI: including mirtazapine

Table 3 Time to event and duration of event (in months)

\begin{tabular}{llllllll}
\hline $\begin{array}{l}\text { Clinical events } \\
\text { (in months) }\end{array}$ & Mean ${ }^{\mathrm{a}}$ & SD & Min. & Max. & $\begin{array}{l}95 \% \\
\text { CI }\end{array}$ & Median \\
\hline $\begin{array}{l}\text { Time to achieve remission/therapeutic change } \\
\text { In first therapeutic }\end{array}$ & 1.5 & 1.2 & 0.5 & 12.0 & $1.3-1.7$ & 1.4 \\
step [14] & & & & & & \\
In second \\
therapeutic step
\end{tabular}

Max. maximum, Min. minimum, $S D$ standard deviation

${ }^{a}$ The values were validated by experts and were in accordance with the guidelines in depression

model to estimate the cost effectiveness of venlafaxine, citalopram, escitalopram, and fluoxetine.

\subsubsection{Medical Management}

Given the absence of therapeutic guidelines and published data related to the treatment of MDD patients in Belgium, the results of a Belgian survey were used to simulate the evolution of patients through the decision tree (Table 2) [14]. In this questionnaire, physicians were first asked which treatment class (SNRIs or SSRIs) they more often used as an initial therapeutic step; they were then asked to consider subsequent treatment steps according to the reason of treatment change (lack of efficacy or tolerability issues). The choice of therapeutic changes (switch, titration, add-on, or transfer to physiotherapist) and time to events (from initiation to second step, and from second step to third step) were also collected. Data from 97 questionnaires completed by general practitioners (GPs) were used to inform the model. Mirtazapine, which is classed as a tetracyclic antidepressant, was pooled with the SNRIs.

The distribution by reason for therapeutic change in patients failing to achieve remission, the selection of the subsequent step, the time to achieve remission, and the treatment durations after remission for each step were derived from the mean value of the corresponding item collected from the 97 questionnaires (see Table 3). The physicians were asked to provide this information by class of initial antidepressant: SSRI (including citalopram $20 \mathrm{mg} /$ day, escitalopram $10 \mathrm{mg} /$ day, fluoxetine $20 \mathrm{mg} /$ day, paroxetine $20 \mathrm{mg} /$ day, and sertraline $50 \mathrm{mg} /$ day) or SNRI (including duloxetine $60 \mathrm{mg} / \mathrm{day}$, and venlafaxine $75 \mathrm{mg} /$ day or mirtazapine $30 \mathrm{mg} /$ day).

Following treatment initiation with an SNRI or mirtazapine, physicians who decided to make a therapeutic change did so because of a lack of efficacy in $59 \%$ of cases and because of tolerability issues in $41 \%$. For SSRIs, the main reason for therapeutic change was lack of efficacy (in $73 \%$ of cases vs. $27 \%$ for tolerability issues).

Based on the local survey and clinical expert opinion (a Belgian professor in psychiatry [21]), we assumed that therapy change or remission both occurred at the end of a 1.5-month assessment period after the initiation of therapy (i.e., from the survey, physicians decided on average to change therapy 6.5 weeks after initiating treatment). Patients achieving remission were assumed to remain on maintenance treatment for 6.1 months (26.5 weeks) and 8.2 months ( 35.5 weeks) in the first and second therapeutic steps, respectively. When not achieving remission on the second treatment step, patients were assumed to stay in non-remission until the end of the 12 months. Finally, based on Limosin et al. [16], it was assumed that patients relapsing did so 4 months after remission.

\subsubsection{Effectiveness}

Utility estimates were derived from Sobocki et al. [22]. In this naturalistic longitudinal observational study conducted in Sweden, 447 depressed patients completed the EuroQoL5D (EQ-5D) health status questionnaire at each visit. In the 
absence of a Swedish social tariff, the authors used UK tariffs derived from Dolan et al. to estimate the utility scores [23, 24]. At the end of a 6-month follow-up, patients achieving remission [improved or very much improved on the Clinical Global Impression-Severity (CGI-S) scale] obtained an average EQ-5D index value of 0.81 (95\% CI 0.77-0.83). Patients not achieving remission reached a utility score of 0.57 (95\% CI 0.52-0.60). In the model, patients relapsing after remission, attempting suicide, or failing to achieve remission were assumed to experience the same level of utility. During the assessment period, the mid-point utility between remission and no remission was used (0.69).

\subsubsection{Costs and Resources Used}

The analysis was run according two perspectives: the NIHDI perspective and the societal perspective. Cost estimates were based on data from the Belgisch Centrum voor Farmacotherapeutische Informatie/Centre Belge d'Information Pharmacothérapeutique (BCFI/CBIP) and published literature. No discount was applied to costs as the time horizon of the study is 1 year (Table 4). All costs were updated when necessary to 2011 prices based on the Belgian Harmonised Index of Consumer Price for health (HICP) [25].

In line with the efficacy assumptions, the costs associated with the therapies that were used to compute the remission rates in the second step were adjusted for each corresponding therapeutic change option. The costs of therapies after switching to SNRIs and to SSRIs were set to the costs of venlafaxine and sertraline, respectively. The costs after titration were set to the costs of the corresponding increased daily dosage of each treatment. For add-on therapies, the average cost of first-step treatments
Table 4 Monthly costs in first and second therapeutic steps from the National Institute for Health and Disability Insurance and societal perspectives
NA not applicable, NIHDI

National Institute for Health and Disability Insurance, SNRI serotonin-norepinephrine reuptake inhibitor, SSRI selective serotonin reuptake inhibitor

a SNRI: including mirtazapine

\begin{tabular}{|c|c|c|c|c|c|}
\hline \multirow[t]{2}{*}{ Therapy costs } & \multirow{2}{*}{$\begin{array}{l}\text { Daily } \\
\text { dose } \\
(\mathrm{mg})\end{array}$} & \multirow{2}{*}{$\begin{array}{l}\text { No. of } \\
\text { daily } \\
\text { intakes }\end{array}$} & \multicolumn{2}{|c|}{ Monthly costs (in $€$ ) } & \multirow[t]{2}{*}{ References } \\
\hline & & & NIHDI & Societal & \\
\hline \multicolumn{6}{|l|}{ In first step } \\
\hline \multicolumn{6}{|l|}{$\mathrm{SNRI}^{\mathrm{a}}$} \\
\hline Duloxetine & 60 & 1 & 34.45 & 46.55 & \multirow[t]{3}{*}{ NIHDI [29], Onkelinx [30] } \\
\hline Venlafaxine & 75 & 1 & 8.18 & 11.11 & \\
\hline Mirtazapine & 30 & 1 & 11.18 & 15.05 & \\
\hline \multicolumn{6}{|l|}{ SSRI } \\
\hline Citalopram & 20 & 1 & 8.03 & 10.92 & \\
\hline Escitalopram & 10 & 1 & 14.03 & 19.76 & \\
\hline Fluoxetine & 20 & 1 & 4.70 & 6.35 & \\
\hline Paroxetine & 20 & 1 & 8.50 & 11.45 & \\
\hline Sertraline & 50 & 1 & 6.99 & 9.52 & \\
\hline \multicolumn{6}{|l|}{ In second step } \\
\hline Switch to SNRI (venlafaxine) & 75 & 1 & 8.18 & 11.11 & \multirow[t]{5}{*}{ NIHDI [29], Onkelinx [30] } \\
\hline Switch to SSRI (sertraline) & 50 & 1 & 6.99 & 9.52 & \\
\hline Combination with bupropion & 300 & 1 & 31.37 & 40.44 & \\
\hline Combination with psychotherapy & NA & NA & 51.50 & 71.72 & \\
\hline Augmentation with quetiapine & 150 & 1 & 44.90 & 47.29 & \\
\hline \multicolumn{6}{|l|}{ Titration } \\
\hline \multicolumn{6}{|l|}{$\mathrm{SNRI}^{\mathrm{a}}$} \\
\hline Duloxetine & 60 & 2 & 68.90 & 93.10 & \\
\hline Venlafaxine & 150 & 1 & 13.00 & 17.37 & \\
\hline Mirtazapine & 45 & 1 & 9.71 & 13.14 & \\
\hline \multicolumn{6}{|l|}{ SSRI } \\
\hline Citalopram & 40 & 1 & 17.05 & 21.43 & \\
\hline Escitalopram & 20 & 1 & 28.06 & 39.51 & \\
\hline Fluoxetine & 20 & 2 & 9.39 & 12.70 & \\
\hline Paroxetine & 30 & 1 & 10.53 & 14.18 & \\
\hline Sertraline & 100 & 1 & 8.49 & 11.55 & \\
\hline Switch to psychotherapy alone & NA & NA & 39.50 & 55.40 & NIHDI [29] \\
\hline Transfer to specialist care & NA & NA & 246.70 & 309.60 & Demyttenaere et al. [12] \\
\hline
\end{tabular}


was included (bupropion $150 \mathrm{mg} /$ day for combination with antidepressant, quetiapine $300 \mathrm{mg} /$ day for augmentation with a non-antidepressant). Treatment costs after combination with psychotherapy were computed as the average costs of a visit to the psychotherapist and the average costs of treatment in first line. When patients were switched to psychotherapy alone, the cost of a visit to the psychotherapist was applied. The cost of specialist care after treatment failure in step 2 (no remission or relapse after remission) or suicide attempt was based on the total direct cost of the "expected costs of secondary care" from Demyttenaere et al. [12], who developed a 6-month decision tree model adapted from Hemels et al. [26] to assess the cost effectiveness of escitalopram for first-line treatment of MDD in Belgium. Costs in patients failing to achieve remission were $€ 886$ and $€ 706$ for 3 months, from the societal and insurance system perspectives, respectively, and included the costs of antidepressant drug (i.e., $€ 151$ and $€ 113$ for 3 months), hospitalization (i.e., $€ 365$ and $€ 365$ for 3 months) and ambulatory care (i.e., €370 and $€ 228$ for 3 months). The monthly costs were computed and inflated to 2011 prices using the Belgian HICP.

The cost of a suicide attempt was derived from the same source [12] and the costs associated with fatal suicide ( $€ 3,072$; acute costs plus follow-up for the health sector) were obtained from the report by De Smedt et al. [27]. The cost of suicide was assumed to be similar from both perspectives (NIHDI and societal).

Based on expert opinion, the cost of a visit to a GP and to a psychotherapist were derived from the costs associated to beneficiaries without and with preferential status, respectively, for the NIHDI and the societal perspective on 1 December 2011 (Table 5). The numbers of GP and psychotherapist visits by therapeutic options were based on Demyttenaere et al. [12] and expert opinion (see Table 5). Patients were assumed to visit their GP once a month during the initiation phase on first-step therapy, and then a further three GP visits until the end of the 12 months for patients on maintenance treatment, on titration, on add-on, or who had switched therapy. Patients with psychotherapy alone or on specialist care were assumed to have only one visit to the GP until the end of the time horizon. Finally, it was assumed that the proportion of patients on psychotherapy visit a psychotherapist once per month.

The total number of workdays lost per month and health condition was derived from Demyttenaere et al. [12]. The indirect costs reflecting the loss of productivity were associated only to the costs of work absenteeism (i.e., limited societal perspective). The average daily cost of absenteeism per employee (i.e., average daily income guaranteed by the employer for a period of absenteeism of 30 calendar days) was estimated at $€ 264$ according to the
Table 5 Resource utilization. Price from National Institute for Health and Disability Insurance [31] and number of visit from Demyttenaere et al. [12]

\begin{tabular}{llll}
\hline Resource utilization & \multicolumn{2}{l}{$\begin{array}{l}\text { Cost per unit } \\
\text { (in } € \text { ) }\end{array}$} & No. of visits \\
\cline { 2 - 3 } & NIHDI & Societal & \\
\hline General practitioner visits & $16.98^{\mathrm{a}}$ & $22.98^{\mathrm{b}}$ & \\
Treatment initiation in first step & & 1 per month \\
Maintenance treatment & & 3 (in total) \\
Switch & & 3 (in total) \\
Titration & & 3 (in total) \\
Add-on & & 3 (in total) \\
Switch to psychotherapy alone & & 1 (in total) \\
Specialist care & & 1 (in total) \\
Psychotherapist visits & $39.5^{\mathrm{c}}$ & $55.38^{\mathrm{d}}$ & \\
Psychotherapist & & & 1 per month \\
\hline
\end{tabular}

NIHDI National Institute for Health and Disability Insurance

a NIHDI: reference code 101076 (licensed generalist; beneficiaries without preferential status)

b NIHDI: reference code 101076 (licensed generalist; fees)

c NIHDI: average of reference code 102690 (licensed specialist in psychiatric) and reference code 109631 (psychotherapy; beneficiaries without preferential status)

d NIHDI: average of reference code 102690 (licensed specialist in psychiatric) and reference code 109631 (psychotherapy; fees)

friction costs, and accounted for the proportion of patients employed [28] (Table 6).

\subsubsection{Sensitivity Analyses}

As this analysis consisted of multiple comparisons, univariate sensitivity analyses cannot be presented using a tornado diagram given that the costs and outcomes vary for each of the assessed strategies. Therefore, it was decided to conduct limited scenario analyses and further explore the effect of uncertainty through probabilistic sensitivity analysis (PSA). Two scenario analyses were conducted on the costs (costs of specialist care from the NIHDI perspective, and absenteeism costs from the societal perspective) and one on the probability of attempted suicide following failure to achieve remission or relapse.

The distributions selected for the PSA were as follows. The efficacy in the first therapeutic step for escitalopram was drawn from a beta distribution, for which parameters were based on the $95 \%$ confidence interval from the TLV meta-analysis. In order to reflect the uncertainty around the relative efficacy between the comparators and escitalopram, the relative risks of remission versus escitalopram were computed. The corresponding variances were estimated using the delta method [32]. As the uncertainty in the attempted suicide rate was due more to the 
Table 6 Number of absenteeism days per month from Demyttenaere et al. [12]

\begin{tabular}{ll}
\hline Type of medical management & $\begin{array}{l}\text { Number of absenteeism } \\
\text { days per month }\end{array}$ \\
\hline Treatment initiation step 1 & 1.3 \\
Maintenance treatment & 1.3 \\
Therapeutic changes & \\
Switch & 2.7 \\
Titration & 2 \\
Add-on & 2 \\
Switch to psychotherapy & 2.7 \\
Specialist care & 10 \\
\hline
\end{tabular}

generalizability of the rates observed by Khan et al. [17] than to sample variability, a uniform distribution of $\pm 50 \%$ of the base-case value was selected. The risk of death in patients attempting suicide was drawn from a beta distribution using the data from the same study [17]. To reflect the different options of the second therapeutic step, the medication changes were drawn from a Dirichlet distribution [33], the parameters of which were derived from the local survey.

The details of the parameters of the PSA are available in the Technical Appendix (Electronic Supplementary Materials Tables I-IV).

\section{Results}

\subsection{Base Case}

One typical patient was run through the model and the corresponding mean costs and outcomes over the 1-year time horizon on the different treatments are reported in Table 7. The total costs per assessed treatment are shown in Fig. 2.
The number of QALYs varied from 0.685 for fluoxetine to 0.701 for escitalopram.

From the NIHDI perspective, the main cost driver was specialist care, which accounted for $70 \%$ (duloxetine) to $79 \%$ (fluoxetine) of the total costs and varied from $€ 824$ in patients on escitalopram to $€ 970$ in patients on fluoxetine. The costs of suicide attempts were relatively stable across treatments and varied slightly with treatment efficacy: from $€ 103$ for the escitalopram strategy to $€ 114$ for the fluoxetine and citalopram strategies. The GP costs were very similar across treatments ( $€ 80$ or $€ 81$ ).

Escitalopram dominated all the comparators (less costly and more effective), except venlafaxine, which was slightly less costly ( $€ 1,113$ vs. $€ 1,129$ ), resulting in an incremental cost-effectiveness ratio (ICER) of escitalopram versus venlafaxine of $€ 6,352$ per QALY (Table 7). The efficiency frontier on the cost-effectiveness plane in Fig. 3 allows comparison of multiple treatment options [34]. Strategies are first sorted by descending costs to exclude dominated strategies and strategies subject to extended dominance (i.e., dominated by a linear combination of two existing strategies) before calculating the ICERs between two consecutive strategies (i.e., in our model, only the ICER between the escitalopram and venlafaxine strategies was computed as all the other strategies were dominated by escitalopram). The optimal strategy is identified as the strategy associated with the highest ICER below the maximum willingness to pay (WTP) for an extra QALY. In this analysis, assuming the maximum WTP exceeds $€ 6,500$, the optimal strategy is escitalopram.

From the societal perspective, productivity loss explained $90 \%$ of the total costs and was driven by the probability of remission. As a result, escitalopram was associated with the lowest cost due to productivity loss $(€ 11,831)$. The cost of productivity loss for other treatments varied from $€ 12,118$ (venlafaxine) to $€ 13,330$ (fluoxetine). Escitalopram dominated all comparators from the societal perspective.

Table 7 Results of the base-case for escitalopram and the seven comparators; total costs from the National Institute for Health and Disability Insurance and societal perspective and quality-adjusted life-years

\begin{tabular}{llllllll}
\hline NIHDI & Total costs $(€)$ & QALYs & ICER & Societal & Total costs $(€)$ & QALYs & ICER \\
\hline Venlafaxine & 1,113 & 0.698 & - & Escitalopram & 13,245 & 0.701 & - \\
Escitalopram & 1,129 & 0.701 & $€ 6,352$ & Venlafaxine & 13,503 & 0.698 & Dominated \\
Mirtazapine & 1,134 & 0.697 & Dominated & Mirtazapine & 13,632 & 0.697 & Dominated \\
Sertraline & 1,166 & 0.693 & Dominated & Sertraline & 14,074 & 0.693 & Dominated \\
Paroxetine & 1,179 & 0.692 & Dominated & Duloxetine & 14,088 & 0.695 & Dominated \\
Fluoxetine & 1,233 & 0.685 & Dominated & Paroxetine & 14,147 & 0.692 & Dominated \\
Citalopram & 1,247 & 0.686 & Dominated & Citalopram & 14,836 & 0.686 & Dominated \\
Duloxetine & 1,257 & 0.695 & Dominated & Fluoxetine & 14,863 & 0.685 & Dominated \\
\hline
\end{tabular}

ICER incremental cost-effectiveness ratio, NIHDI National Institute for Health and Disability Insurance, $Q A L Y s$ quality-adjusted life-years 
Fig. 2 Details of costs from the (a) National Institute for Health and Disability Insurance and (b) societal perspective. GP general practitioner, $S N R I$ serotonin-norepinephrine reuptake inhibitor, SSRI selective serotonin reuptake inhibitor

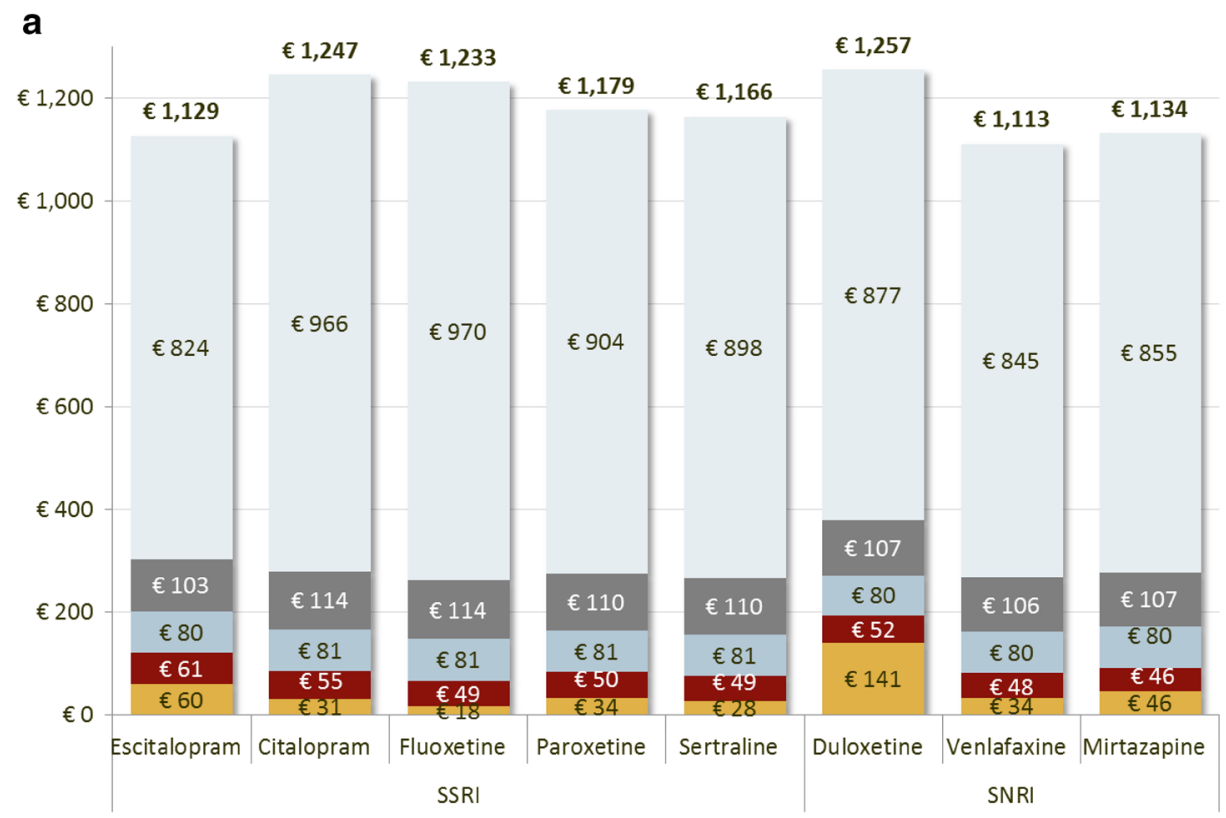

Treatment in Step1 $\quad$ Treatment in Step2 $\square$ Visits to the GP $\quad$ Suicide attempt Specialist care

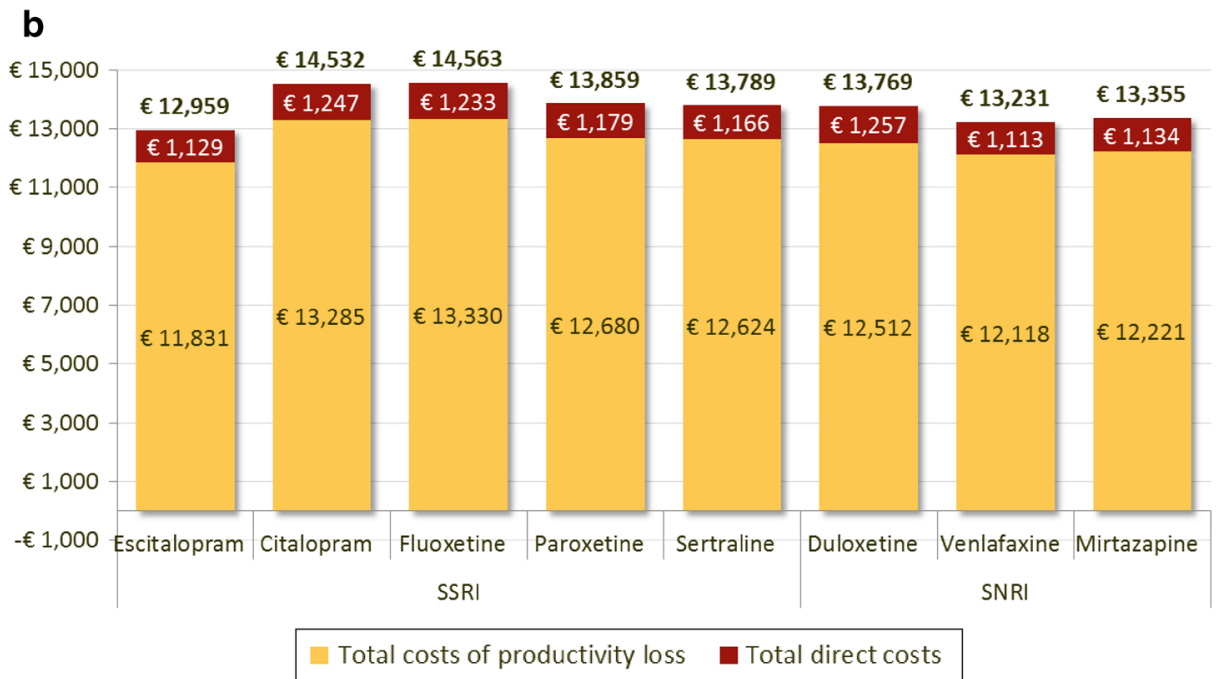

\subsection{Sensitivity Analyses}

From the NIHDI perspective, the total costs were sensitive to the costs of specialist care (i.e., an increase of $50 \%$ of the specialist care costs led to an increase ranging from 35 to $40 \%$ of the total costs). When increasing the specialist costs by $100 \%$, escitalopram dominated all the other strategies. When increasing the costs of absenteeism by $50 \%$, total societal costs rose by approximately $45 \%$, and escitalopram kept dominating all of the other treatments. When raising the risk of attempted suicide from 6.3 to $10 \%$, QALYs decreased by $0.1 \%$.

When making pairwise comparisons from the NIHDI perspective, escitalopram was dominant (i.e., more effective and less costly) in more than $50 \%$ of the 1,000 simulations for each comparator, except versus venlafaxine $(27.0 \%)$ and mirtazapine (43.5\%) (Table 8). Disregarding venlafaxine or mirtazapine, escitalopram was dominated in less than $10 \%$ of cases. When compared with SSRIs, escitalopram was more effective in $>90 \%$ of the simulations (range 90.5-99.9\%). Compared to SNRIs, escitalopram was more effective in $69.4-81.4 \%$ of cases.

From the NIHDI perspective, the cost-effectiveness planes of each assessed strategy overlapped due to the overlapping of the $95 \%$ confidence intervals related to the probability of remission (Fig. 4). The scatter of plots for duloxetine was located above the others due to the higher price of the drug. The cost-effectiveness plane shows an 


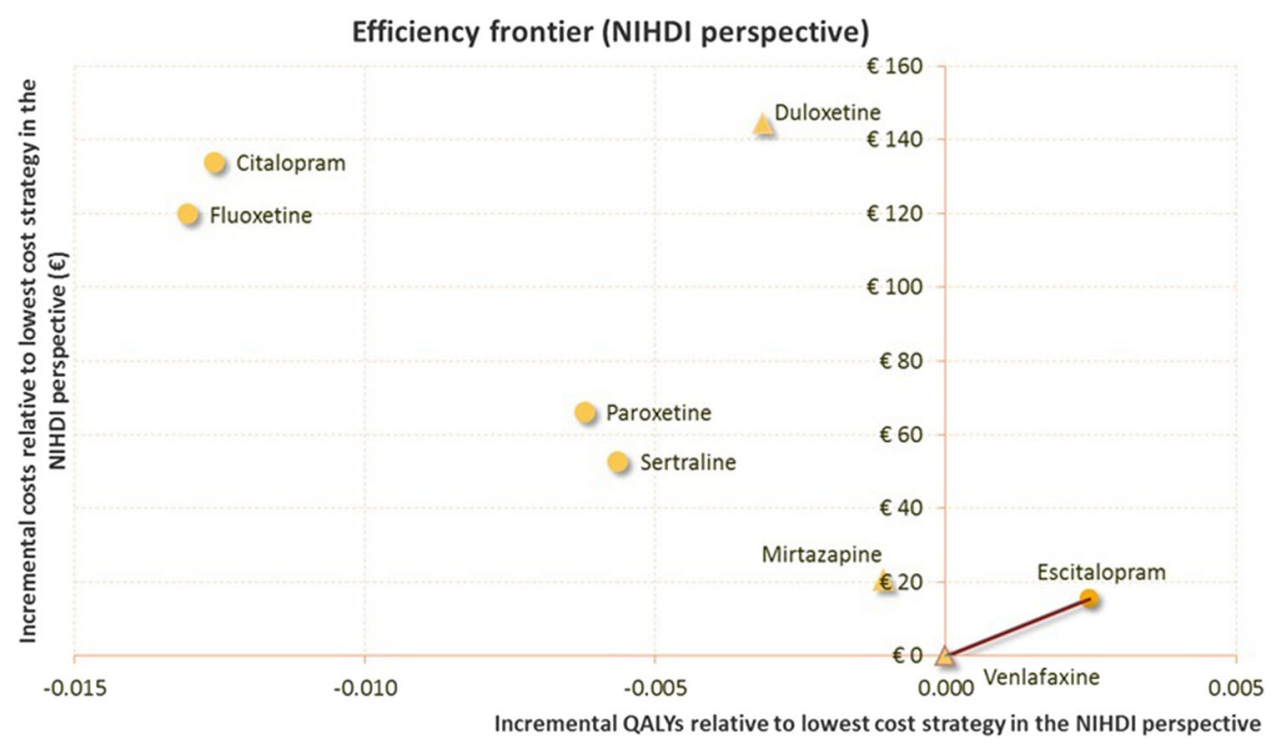

Fig. 3 Efficiency frontier from the National Institute for Health and Disability Insurance perspective. NIHDI National Institute for Health and Disability Insurance, $Q A L Y s$ quality-adjust life-years,

important relation whereby the increase in QALYs gained is mirrored by a decrease in incremental total costs. As treatment efficacy drove the total cost of treatment through specialist care (i.e., a less efficient treatment will lead to an increase in specialist care resources important enough that the medication costs effects will not be big enough to attenuate), uncertainty in drug efficacy was translated into a relatively large variation in terms of costs.

From the societal perspective, escitalopram was dominant to all of the comparators in $>60 \%$ of the simulations; i.e., ranging from $62.6 \%$ (venlafaxine) to $99.6 \%$ (fluoxetine).

At a threshold of $€ 30,000$ [35] per QALY and from the NIHDI perspective, the PSA showed that in comparison to the each of the comparators, escitalopram had a probability of between $61 \%$ (vs. venlafaxine) and $100 \%$ (vs. fluoxetine) of being identified as the optimal strategy (Fig. 4). Moreover, escitalopram had the highest probability of being the optimal strategy when compared to all treatments from a threshold of $€ 22,000$; e.g., at a threshold of $€ 22,000$, escitalopram has the highest net benefit [QALY $\times 22,000-$ COST] in $30 \%$ of the 1,000 simulations (Fig. 4).

From the societal perspective, the probability that escitalopram was identified as the optimal strategy at the same threshold ranged from $64 \%$ (vs. venlafaxine) to $100 \%$ (vs. fluoxetine).

\section{Discussion}

Depression is a burdensome disorder, characterized by relapses or recurrences [36]. The efficacy of treatment significantly affects the total costs of the disease, mainly through the cost of specialist care and hospitalization from a national insurance perspective, and through the high cost of work absenteeism from a societal perspective. In Belgium, escitalopram was approved by the NIHDI in May 2002 for the treatment of depression [37] and many therapeutic options are currently available to people suffering from MDD, yet at the time of writing, none are officially recommended by the Belgian health authorities.

In 2005, Demyttenaere et al. [12] evaluated the cost effectiveness of escitalopram, citalopram, and venlafaxine (which became generic in January 2009) in the treatment of MDD in Belgium. The effectiveness outcome of interest was successful treatment, defined as patients that achieved remission within 8 weeks of treatment and did not relapse over the following 6 months. The study concluded that escitalopram dominated citalopram and venlafaxine from the NIHDI and societal perspectives, with higher success rates and lower costs achieved for escitalopram. Similarly, our study concluded that escitalopram dominated citalopram from both perspectives and venlafaxine from the societal perspective. Escitalopram was found to be cost effective versus venlafaxine from the NIHDI perspective (€6,352/QALY). However, the total cost difference between the two treatments was small and varied from $1.5 \%$ in our study to $5.1 \%$ in the study conducted by Demyttenaere et al. [12]. Our results were consistent with analyses conducted for other countries $[1,12,36]$. A network meta-analysis conducted by the TLV compared the efficacy of 18 antidepressants, based on 85 international studies published between 1975 and 2008 [1]. After developing a mixed treatments comparison and a health 
Table 8 Pairwise comparisons of escitalopram versus each of the seven comparators in the National Institute for Health and Disability Insurance and societal perspectives

NIHDI National Institute for Health and Disability Insurance

\begin{tabular}{lllll}
\hline & $\begin{array}{l}\text { Escitalopram } \\
\text { less costly (\%) }\end{array}$ & $\begin{array}{l}\text { Escitalopram } \\
\text { more effective }(\%)\end{array}$ & $\begin{array}{l}\text { Escitalopram } \\
\text { dominant }(\%)\end{array}$ & $\begin{array}{l}\text { Escitalopram } \\
\text { dominated (\%) }\end{array}$ \\
\hline NIHDI & & & & 1.00 \\
Citalopram & 90.20 & 99.00 & 90.20 & 0.10 \\
Fluoxetine & 86.30 & 99.90 & 86.30 & 6.80 \\
Paroxetine & 66.70 & 93.20 & 66.70 & 9.50 \\
Sertraline & 56.20 & 90.50 & 56.20 & 0.80 \\
Duloxetine & 99.20 & 81.40 & 81.40 & 30.60 \\
Venlafaxine & 27.00 & 69.40 & 27.00 & 29.50 \\
Mirtazapine & 43.50 & 70.50 & 43.50 & 0.90 \\
Societal & & & & 0.10 \\
Citalopram & 98.50 & 99.10 & 98.50 & 7.40 \\
Fluoxetine & 99.60 & 99.90 & 99.60 & 7.40 \\
Paroxetine & 91.10 & 92.60 & 91.10 & 7.70 \\
Sertraline & 89.30 & 92.60 & 89.30 & 31.90 \\
Duloxetine & 92.30 & 84.30 & 84.30 & 28.00 \\
Venlafaxine & 63.60 & 67.10 & 62.60 & 66.20 \\
Mirtazapine & 67.60 & 70.60 & &
\end{tabular}

economic model including the new generation of antidepressants used in Sweden (citalopram, duloxetine, escitalopram, fluoxetine, fluvoxamine, mirtazapine, paroxetine, reboxetine, sertraline, and venlafaxine), the authors concluded that escitalopram dominated all comparators but mirtazapine, against which escitalopram was found to be cost effective. The difference in the results (i.e., mirtazapine not dominated by escitalopram in Sweden, while the only non-dominated drug vs. escitalopram was venlafaxine in Belgium) is directly due to the differences between the drugs' unit costs between the two countries (i.e., the patent of venlafaxine expired in 2008 in Sweden).

A more recent network meta-analysis compared the efficacy of 12 new-generation antidepressants (bupropion, citalopram, duloxetine, escitalopram, fluoxetine, fluvoxamine, milnacipran, mirtazapine, paroxetine, reboxetine, sertraline, and venlafaxine), based on 117 randomized controlled trials worldwide from 1991 to 2007 [13]. The authors concluded that mirtazapine, escitalopram, venlafaxine, and sertraline were significantly more effective than the other therapies. When taking into account both efficacy and tolerability, they found a clinical advantage of using sertraline or escitalopram, both SSRIs.

A recent publication by Nuijten et al. [36] showed that in The Netherlands, escitalopram was associated with a gain of 0.0166 QALYs versus citalopram and of 0.0062 versus venlafaxine (compared with 0.0151 and 0.0025 , respectively, in our study). Although not directly comparable due to the country settings, our results relative to escitalopram were also consistent with this publication; i.e., slightly higher QALYs in favor of escitalopram, ranging in the model from 0.0025 (venlafaxine) to 0.0155 (fluoxetine).

Other cost-effectiveness analyses comparing escitalopram versus venlafaxine found similar results between the two agents in terms of success rate and cost in the treatment of MDD. In a British evaluation, the success rate of escitalopram and venlafaxine (i.e., MADRS score $\leq 12$ ) was found similar (i.e., $63.5 \%$ ) after 6 months, with a small saving in favor of escitalopram (ranged from $£ 53$ to $£ 61$ ) [38]. In Norway, the success rate after 6 months was $64.2 \%$ for escitalopram and $62.1 \%$ for venlafaxine, with associated average total costs of 19,661 Norwegian kroner (NOK) and NOK20,989, respectively [20].

Finally, clinical studies comparing the efficacy between escitalopram and citalopram have shown significant superiority of escitalopram over citalopram in terms of response rate (defined as $\geq 50 \%$ improvement in MADRS total score) $[39,40]$.

To our knowledge, our study is the first to report a costeffectiveness assessment of treatments of MDD in Belgium expressed in terms of incremental cost per QALY. In addition, this study considered a broad range of comparators (citalopram, venlafaxine, fluoxetine, paroxetine, sertraline, duloxetine, venlafaxine, and mirtazapine) to achieve a better understanding of the optimal treatment strategy of MDD from a health economic standpoint. Moreover, the adaptation of a model structure and the use of a meta-analysis developed by a public and independent institute (i.e., TLV health technology assessment), guarantee a certain level of transparency and technical rigor. Furthermore, the majority of guidelines suggest that 

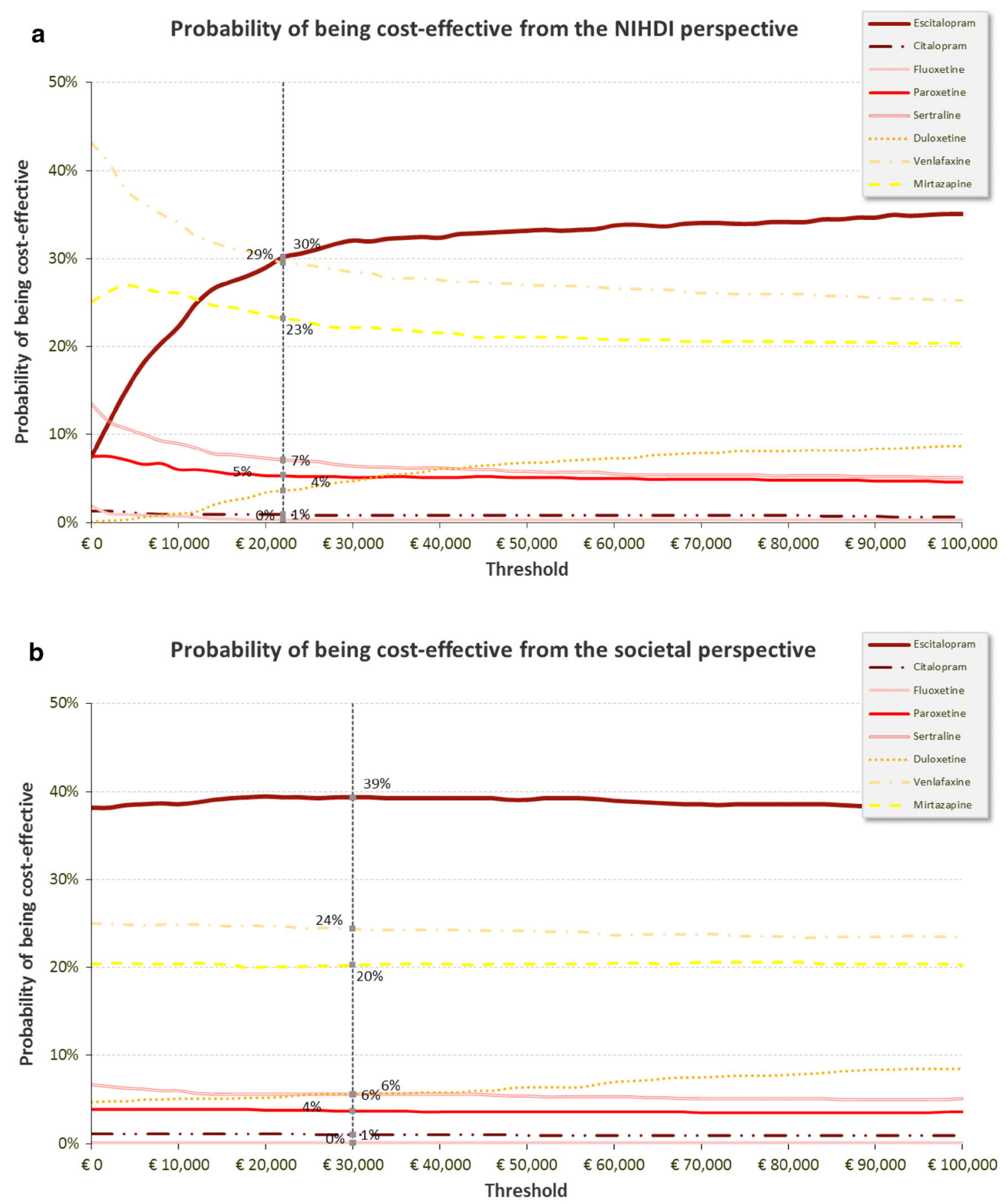

Fig. 4 Cost-effectiveness acceptability curve from the (a) National Institute for Health and Disability Insurance and (b) societal perspectives. NIHDI National Institute for Health and Disability Insurance

treatment effects from clinical trials are generalizable across country settings [41].

However, our study is subject to some limitations due to the assumptions defined when data were not available (even if these assumptions were validated by expert opinion). By using treatment effects at 12 weeks and assuming that all patients change medication after 1.5 months should they fail to achieve remission, we may be overestimating the utility. However, another source of the model, the STAR*D [18] study, used an average time to remission of 6 weeks and, moreover, in the management of depression it is recommended to change medication strategy if no improvement is observed after 2-6 weeks on treatments [42]. Furthermore, in practice, a proportion of patients might remain on the same treatment even if they do not achieve remission. As an example, according to the local 
survey used to inform this study, approximately $74 \%$ of patients remain on the first initiated treatment, while remission rates derived from clinical trials (from the TLV meta-analysis) did not exceed $50 \%$. However, as these practices are difficult to justify, they were not further investigated [1, 14].

Also in the STAR*D study, the rate of remission following psychotherapy alone was higher than the rate following the combination of citalopram and psychotherapy (0.4190 vs. 0.2940$)$. However, patients were free to choose psychotherapy (non-randomized trial), which may account for the higher rate of remission in the case of psychotherapy alone. As in real clinical practice, self-selection is present, so the efficacy of psychotherapy alone was set to $41.9 \%$ in our model.

Since there were no recent data available for the costs of hospitalization for patients with MDD in Belgium, we updated the secondary care costs obtained from Demyttenaere et al. [12] based on the HICP for health goods. Another limitation due to missing data lies in assuming a similar risk of relapse and utility among treatments and a similar rate of attempted suicide following treatment failure (i.e., remission with or without suicide attempt, or relapse). The rates of suicide were based on trial submitted to the FDA, which may exclude suicidal patients at baseline. Thus, the risk of suicide may be slightly underestimated. However, as highlighted above, this risk was assumed to be similar across treatments. Moreover, due to a lack of data at the time of analysis, the cost of suicide was assumed to be similar for both perspectives. A 2013 study assessing the cost effectiveness of a helpline for suicide prevention in Belgium estimated the costs related to suicide at $€ 2,600$ (vs. $€ 3,072$ in our model) and $€ 60,537$, from the NIHDI and societal perspectives, respectively, which suggests a clear under-estimation of the costs from the societal perspective [43].

A 1-year time horizon may not be long enough to capture long-term effects of agents; however, this timeframe was used because it was long enough to capture a large proportion of patient relapses, and short enough to be supported by credible clinical trial data, and so limited the number of assumptions.

Psychological-based cognitive behavioral therapy (PBCBT) was not included in the list of comparators for first line-therapy (only second line) to be consistent with our primary source of data (i.e., the TLV did not include PBCBT in its meta-analysis) and thus avoid heterogeneity by considering several data sources.

The distributions of reasons for medication changes were based on a sample of 97 GPs, which is limited to entirely represent clinical practices in Belgian. However, it was the best available data to reflect local practices and treatment pathways for a typical patient with MDD in
Belgium, and the variations in GP's responses were tested in the sensitivity analyses.

Adverse events were not considered in the analyses, as their associated costs represent a low proportion of the total costs of the disease [36]. Moreover, this is not expected to change the conclusions since escitalopram is generally well-tolerated and associated with mild and transient adverse events [44].

Finally, our model faced the same limitations as highlighted in the TLV report conclusion, that is to say the use of data from clinical studies that may not accurately reflect the effects of antidepressants in real life (e.g., the differences in terms of treatment effects came from studies with follow-up periods less than 2 months, which could be considered too short to capture the impact of the different treatments on the remission rate).

The multiple comparison analyses via the efficiency frontier on the cost-effectiveness plan enabled a simultaneous assessment of all the treatment options. The same approach should be used when running scenario or deterministic sensitivity analyses and therefore the full costefficiency frontier may move so that the relevant ICERs reported compare pairs of strategies other than the base case. Therefore, the results cannot simply be reported on a tornado diagram [45]. For this study, we decided to conduct a limited scenario analysis to assess the sensitivity of the results to parameters for which no strong data were readily available (probability of suicide following failure to achieve remission or relapse, costs of hospitalization and costs of absenteeism). Parameter uncertainty was then analyzed through PSAs (e.g., overlapping of the confidence intervals between remission rates from the TLV metaanalyses, variation between clinician answers in the Belgian survey). Finally, in order to not add uncertainty in the model, no subgroup analysis, which would have required additional assumptions and data, was conducted.

\section{Conclusion}

Using multiple comparisons, escitalopram was associated with the highest probability of being the optimal strategy from the NIHDI and societal perspectives. This analysis, based on new clinical data and following the guidelines of the Belgian $\mathrm{KCE}$, provides additional information that may be used to guide value-based pricing and reimbursement as well as the choice of treatments in the management of MDD in Belgium.

Acknowledgments The study was funded by Lundbeck SAS. Pr. Lieven Annemans received an unrestricted grant from Lundbeck. Mélanie Brignone and Ann De Pauw were employed by Lundbeck. Sylvain Druais and Aline Gauthier received funding for this project by Lundbeck. Pr. Koen Demyttenaere received fees from Lundbeck 
for attending advisory boards. The overall guarantor of this work is Mélanie Brignone.

Open Access This article is distributed under the terms of the Creative Commons Attribution Noncommercial License which permits any noncommercial use, distribution, and reproduction in any medium, provided the original author(s) and the source are credited.

\section{References}

1. Wessling A, Ramsberg J. The review of antidepressants: the Dental and Pharmaceutical Benefits Agency. Solna: TLV; 2008.

2. WHO. World Health Organisation-mental health-depression. 2012. http://www.who.int/mental_health/management/depression/ definition/en/. Accessed 12 Jul 2012.

3. Wittchen HU, Jacobi F, Rehm J, Gustavsson A, Svensson M, Jonsson B, et al. The size and burden of mental disorders and other disorders of the brain in Europe 2010. Eur Neuropsychopharmacol. 2011;21(9):655-79.

4. Cipriani A, Santilli C, Furukawa TA, Signoretti A, Nakagawa A, McGuire $\mathrm{H}$, et al. Escitalopram versus other antidepressive agents for depression. Cochrane Database Syst Rev. 2009(2):CD006532.

5. Depression and Bipolar Support Alliance (DBSA). Depression; 2012. http://www.dbsalliance.org/site/PageServer?pagename= education_depression. Accessed Nov 2012.

6. Whiteford HA, Degenhardt L, Rehm J, Baxter AJ, Ferrari AJ, Erskine HE, et al. Global burden of disease attributable to mental and substance use disorders: findings from the Global Burden of Disease Study 2010. Lancet. 2013;382(9904):1575-86.

7. Bruffaerts R, Bonnewyn A, Demyttenaere K. The epidemiology of depression in Belgium. A review and some reflections for the future. Tijdschr Psychiatr. 2008;50(10):655-65.

8. Boutsen M, Laasman JM, Reginster N. Données socio-économiques et étude longitudinale de la prescription des antidépresseurs. Brussels: Mutualité socialiste (MutSoc), Etudes Dd; 2006.

9. NIHDI. Monitoring Of Reimbursement Significant Expenses M.O.R.S.E.report. 2008(1): NIHDI2008.

10. NIHDI. Tableaux de bord pharmaceutiques. Délivrances pharmaceutiques dans le secteur ambulatoire. Brussels: National Institute for Health and Disability Insurance (NIHDI), médicaments Cdédpmemd; 2009.

11. Shih YC, Bekele NB, Xu Y. Use of Bayesian net benefit regression model to examine the impact of generic drug entry on the cost effectiveness of selective serotonin reuptake inhibitors in elderly depressed patients. Pharmacoeconomics. 2007;25(10):843-62.

12. Demyttenaere K, Hemels ME, Hudry J, Annemans L. A costeffectiveness model of escitalopram, citalopram, and venlafaxine as first-line treatment for major depressive disorder in Belgium. Clin Ther. 2005;27(1):111-24.

13. Cipriani A, Furukawa TA, Salanti G, Geddes JR, Higgins JP, Churchill R, et al. Comparative efficacy and acceptability of 12 new-generation antidepressants: a multiple-treatments meta-analysis. Lancet. 2009;373(9665):746-58.

14. Department of Psychiatry UKBcs. Therapeutic management of major depressive disorder in Belgium. UKBcs: Leuven; 2011.

15. KCE. Guidelines for pharmacoeconomic evaluations in Belgium; 2008. http://www.ispor.org/peguidelines/source/Belgium_Guide lines-for-Pharmacoeconomics-Evaluation-in-Belgium_2008_ English.pdf. Accessed Mar 2012.

16. Limosin F, Loze JY, Zylberman-Bouhassira M, Schmidt ME, Perrin E, Rouillon F. The course of depressive illness in general practice. Can J Psychiatry. 2004;49(2):119-23.
17. Khan A, Khan SR, Leventhal RM, Brown WA. Symptom reduction and suicide risk in patients treated with placebo in antidepressant clinical trials: a replication analysis of the Food and Drug Administration database. Int J Neuropsychopharmacol. 2001;4(2):113-8.

18. Rush AJ, Trivedi MH, Wisniewski SR, Nierenberg AA, Stewart JW, Warden D, et al. Acute and longer-term outcomes in depressed outpatients requiring one or several treatment steps: a STAR*D report. Am J Psychiatry. 2006;163(11):1905-17.

19. Bauer M, El-Khalili N, Datto C, Szamosi J, Eriksson H. A pooled analysis of two randomised, placebo-controlled studies of extended release quetiapine fumarate adjunctive to antidepressant therapy in patients with major depressive disorder. J Affect Disord. 2010;127(1-3): 19-30.

20. Francois C, Toumi M, Aakhus AM, Hansen K. A pharmacoeconomic evaluation of escitalopram, a new selective serotonin reuptake inhibitor. Comparison of cost-effectiveness between escitalopram, citalopram, fluoxetine, and venlafaxine for the treatment of depression in Norway. Eur $\mathrm{J}$ Health Econ. 2003;4(1):12-9.

21. Brignone M, Annemans L, Demyttenaere K, Defraigne G, de Paw A, Gauthier A, et al. Expert meeting on the TLV model adaptation-presentation of the results of the cost-effectiveness analyses. In: 2011, Brussels; 2011.

22. Sobocki P, Ekman M, Agren H, Runeson B, Jonsson B. The mission is remission: health economic consequences of achieving full remission with antidepressant treatment for depression. Int $\mathbf{J}$ Clin Pract. 2006;60(7):791-8.

23. Sobocki P, Ekman M, Agren H, Krakau I, Runeson B, Martensson B, et al. Health-related quality of life measured with EQ$5 \mathrm{D}$ in patients treated for depression in primary care. Value Health. 2007;10(2):153-60.

24. Dolan P, Gudexz C, Kind P, Williams A. A social tariff for EuroQol: results from a UK general population survey. York: Centre for Health Economics, University of York; 1995.

25. Belgian government. The evolution of the general index and the main sub-indices of the Belgian HICP; 2011. http://statbel.fgov.be/ en/modules/publications/statistics/economy/downloads/harmonised_ index_of_consumer_prices.jsp. Accessed Mar 2012.

26. Hemels ME, Kasper S, Walter E, Einarson TR. Cost-effectiveness analysis of escitalopram: a new SSRI in the first-line treatment of major depressive disorder in Austria. Curr Med Res Opin. 2004;20(6):869-78.

27. De Smedt D, Sbarigia U, Annemans L. Kosten-effectiviteit van suïcidepreventie. Faculteit Geneeskunde en Gezondheidswetenschappen. Belgium: Gezondheidsconferentie Suïcidepreventie; 2011.

28. Securex. Report. Absentéisme dans le secteur privé. Belgium: Securex; 2010.

29. NIHDI. 2012. http://www.inami.fgov.be/drug/fr/drugs/index.htm. Accessed Jan 2012.

30. Onkelinx L. Royal Treaty. Federal Overheidsdiensr Sociale Zekerheid/Service Public Federal Securité Sociale. Belgium: Belgian Kingdom; 2012.

31. NIHDI. Visits costs; 2012. http://www.inami.fgov.be/insurer/fr/ rate/index.htm. Accessed Mar 2012.

32. Montana Uo. D.o.M.S. 2012. http://www.math.umt.edu/ patterson/549/Delta.pdf. Accessed June 2012.

33. Briggs A, Claxton K, Sculpher M. Decision modelling for health economic evaluation. Oxford: Oxford University Press; 2006.

34. Eckermann S, Briggs A, Willan AR. Health technology assessment in the cost-disutility plane. Med Decis Making. 2008;28(2): 172-81.

35. Nuijten MJ, Dubois DJ. Cost-utility analysis: current methodological issues and future perspectives. Front Pharmacol. 2011;2:29. 
36. Nuijten MJ, Brignone M, Marteau F, den Boer JA, Hoencamp E. Cost-effectiveness of escitalopram in major depressive disorder in the Dutch health care setting. Clin Ther. 2012;34(6):1364-78.

37. McRae AL. Escitalopram H Lundbeck. Curr Opin Investig Drugs. 2002;3(8):1225-9.

38. Wade AG, Toumi I, Hemels ME. A probabilistic cost-effectiveness analysis of escitalopram, generic citalopram and venlafaxine as a first-line treatment of major depressive disorder in the UK. Curr Med Res Opin. 2005;21(4):631-42.

39. Lam RW, Andersen HF. The influence of baseline severity on efficacy of escitalopram and citalopram in the treatment of major depressive disorder: an extended analysis. Pharmacopsychiatry. 2006;39(5):180-4.

40. Montgomery S, Hansen T, Kasper S. Efficacy of escitalopram compared to citalopram: a meta-analysis. Int J Neuropsychopharmacol. 2011;14(2):261-8.

41. Drummond M, Barbieri M, Cook J, Glick HA, Lis J, Malik F, et al. Transferability of economic evaluations across jurisdictions:
ISPOR Good Research Practices Task Force report. Value Health. 2009;12(4):409-18.

42. Sorensen J, Stage KB, Damsbo N, Le Lay A, Hemels ME. A Danish cost-effectiveness model of escitalopram in comparison with citalopram and venlafaxine as first-line treatments for major depressive disorder in primary care. Nord $\mathrm{J}$ Psychiatry. 2007;61(2):100-8.

43. Pil L, Pauwels K, Muijzers E, Portzky G, Annemans L. Costeffectiveness of a helpline for suicide prevention. J Telemed Telecare. 2013;19(5):273-81.

44. Croom KF, Plosker GL. Escitalopram: a pharmacoeconomic review of its use in depression. Pharmacoeconomics. 2003;21(16):1185-209.

45. Taylor M. What is sensitivity analysis? York; 2009. York Health Economics Consortium. http://www.medicine.ox.ac.uk/bandolier/ painres/download/whatis/What_is_sens_analy.pdf. Accessed Jan 2013. 